\title{
Selective mono-0-alkylation (protection) of carbohydrates catalyzed by stannylene acetals
}

\section{Angelo Amaro T. da Silva*, Tamires de O. B. Dias and Alessandro B. C. Simas}

Universidade Federal do Rio de Janeiro, Núcleo de Pesquisas de Produtos Naturais (NPPN), Lab. Roderick

A. Barnes, Centro de Ciências da Saúde, bloco H,Ilha do Fundão, Rio de Janeiro, RJ 21941-902, Brazil

\section{*amaro.jk@ufrj.br}

Keywords: carbohydrates, stannylene acetal, catalysis

\section{INTRODUCTION}

Carbohydrates and their derivatives play important roles in nature. ${ }^{1}$ The use of such natural materials in the synthesis of complex oligomers, ${ }^{2}$ analogues, or chiral building blocks (in total synthesis) depends on efficient methodologies for selective protection. ${ }^{3}$

Previously, we had demonstrated that selective $O$ alkylation of polyols may be catalyzed by stannylenes. Thus, di-O-benzylation of D-mannitol derivative 1 was carried out efficiently with low load of the tin reagent (only $\sim 15 \mathrm{~mol} \%$ of depolymerized $\mathrm{Bu}_{2} \mathrm{SnO}$ was used) (Scheme 1). ${ }^{4}$

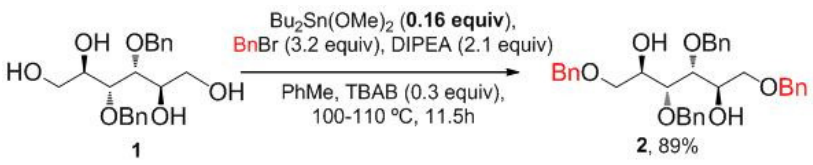

Scheme 1 . Seminal result of catalysis by stannylenes. ${ }^{4}$

Thus, this study aims at the selective mono-protection (O-alkylations) of carbohydrates using stannylene acetals as catalysts. ${ }^{4}$

\section{RESULTS AND DISCUSSION}

Initial experiments employing even lesser amounts of the tin reagent $(10 \mathrm{~mol} \%)$, for the most part, indicated the need of optimization of our original protocol (Schemes 2, 3).
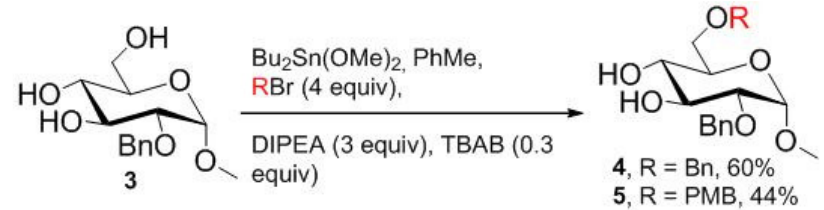

Scheme 2. Selective protection of $O$-methyl D-glucoside 3 catalyzed by stannylenes.

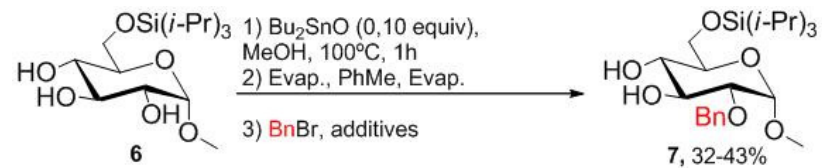

Scheme 3. Selective protection of O-methyl D-glucoside 6 catalyzed by stannylenes.
Thus, notwithstanding the expected formation of regioisomers, we used resisting substrate $\mathbf{8}$ as model for the protocol optimization (Scheme 4). With this work, we managed to attain good yields of $\mathbf{9}$. The results and the investigation strategy will be discussed.
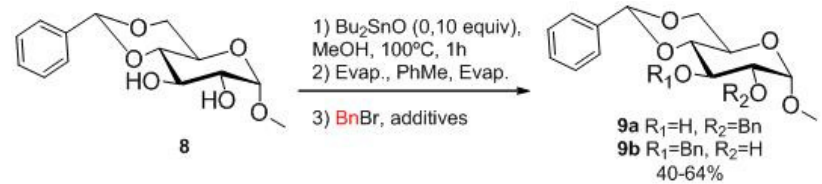

Scheme 4. Model reaction for the optimization of the catalytic reaction.

\section{CONCLUSION}

The feasibility of selective monoprotection (via $O$ alkylation) of carbohydrates catalyzed by stannylenes was established.

\section{ACKNOWLEDGEMENTS}

We thank CNPq, UFRJ and FAPERJ for funding and fellowships.

\section{REFERENCES}

${ }^{1}$ Bertozzi, C. R. Science 2001, 291, 2357-2364

2 Stallforth, P.; Lepenies, B.; Adibekian, A.; Seeberger, P. J. Med. Chem. 2009, 52, 5561-5577.

${ }^{3}$ Wang, C.; Lee, J.; Luo, S.; Kulkarni, S.; Huang, Y.; Lee, C.; Chang, K.; Hung, S. Nature 2007, 446, 896-899 and cited refs..

${ }^{4}$ Simas, A. B.; Silva, A. A. D.; Filho, T. J. D. S.; Barroso, P. T. Tetrahedron Letters 2009, 50, 2744-2746 and cited refs.

\footnotetext{
$14^{\text {th }}$ Brazilian Meeting on Organic Synthesis $-14^{\text {th }}$ BMOS - September 01-05, 2011-Brasilia, Brazil
} 